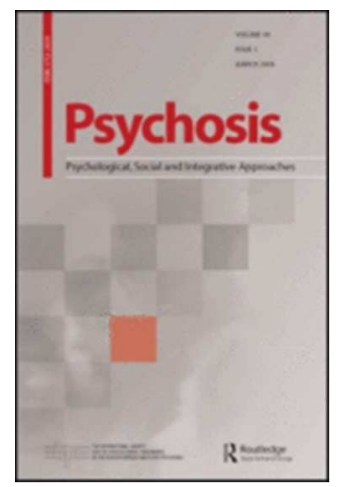

\title{
Religion in the Recovery Journey of Individuals with Experience of Psychosis
}

\begin{tabular}{|r|l|}
\hline Journal: & Psychosis \\
\hline Manuscript ID & RPSY-2015-0009.R2 \\
\hline Manuscript Type: & Research Article \\
\hline Keywords: & psychosis, religion, recovery, grounded theory \\
\hline & $\begin{array}{l}\text { This study investigated the role of religion in recovery from } \\
\text { psychosis. Semi-structured interviews explored the experiences of ten } \\
\text { participants. Data analysis was informed by social constructionist } \\
\text { grounded theory. Several processes through which religion may influence } \\
\text { recovery were identified: use of scriptures and rituals; a genuine } \\
\text { connection with God; the struggle to maintain rituals; guidelines for living; } \\
\text { choice and control; relating to others; enhancing psychological well-being; } \\
\text { and making sense of experiences. Implications are that services should } \\
\text { address religious needs in promoting recovery. This could be achieved } \\
\text { through environmental adaptations, collaboration with religious } \\
\text { representatives and incorporation of religion into psychotherapeutic } \\
\text { approaches. }\end{array}$ \\
\hline \multicolumn{2}{|l}{} \\
\hline
\end{tabular}

\section{SCHOLARONE}

Manuscripts 


\section{Religion in the Recovery Journey of Individuals with Experience of Psychosis}

This study investigated the role of religion in recovery from psychosis. Semistructured interviews explored the experiences of ten participants. Data analysis was informed by social constructionist grounded theory. Several processes through which religion may influence recovery were identified: use of scriptures and rituals; a genuine connection with God; the struggle to maintain rituals; guidelines for living; choice and control; relating to others; enhancing psychological well-being; and making sense of experiences. Implications are that services should address religious needs in promoting recovery. This could be achieved through environmental adaptations, collaboration with religious representatives and incorporation of religion into psychotherapeutic approaches.

Keywords: psychosis; religion; recovery; grounded theory

\section{Introduction}

The term religion has been characterised as the "specific behavioural, social, doctrinal and denominational characteristics...a belief in a supernatural power or transcendent being, truth or ultimate reality, and the expression of such a belief in behaviour and rituals" (Huguelet \& Koenig, 2009, p.1). Recent years have seen a renewed interest in the role of religion in research and service delivery (Cornah, 2006). Historically, this area was largely ignored, perhaps due to professional tendencies to pathologise religious experiences, lack of training and lower numbers of religious affiliation amongst professionals (Lukoff, Lu \& Turner, 1992). However, evidence suggests that religion can contribute to the development of hope, optimism, purpose, meaning, self-esteem and social support (Koenig, McCullough \& Larson, 
2001), all of which are important in recovery. Research into religion and psychosis often focuses on the religious content in symptoms of psychosis (Phillips, Lukoff \& Stone, 2009) whereas exploration of how religion operates in recovery has been neglected.

First-person accounts and qualitative research suggest that religion can be a helpful resource facilitative of recovery (Fallot, 2007; Phillips \& Stein, 2007). Sullivan (1998) found that spirituality [including religion] helped to facilitate coping and decision making, providing social support and developing a sense of coherence. Religion also helps people through crises by acting as a source of hope, meaning and inspiration (Young \& Ensing, 1999).

Those with psychosis often use religion to cope (Tepper, Rogers, Coleman \& Malony, 2001). Pargament et al. (1988) describe three methods of religious coping: self-directing, deferring and collaborating. Collaboration means taking a joint responsibility with God for solving problems. This has been associated with higher levels of psychological well-being (Pieper, 2004), empowerment and involvement in recovery enhancing activities (YangarberHicks, 2004).

Conversely, recovery may be undermined by religion especially where distressing psychotic experiences involve religious content (Brewerton, 1994). Religious individuals may also experience rejection, stigma, marginalisation (Fallot, 2001), feelings of guilt, selfperceptions of sinfulness (Fallot, 2007) and lower levels of functioning (Tepper et al., 2001).

In summary whilst religion may facilitate recovery, it can also have a negative impact on the process. However, it is unclear, under what circumstances and for which individuals the direction of the impact is determined.

\section{Aims and Rationale}


Despite increasing evidence of links between religion and mental health, research has not explored fully the relationship especially with regards to psychosis (Menezes \& MoreiraAlmeida, 2010). Moreover, there is a lack of qualitative investigations which could provide further insights into religion and recovery processes to guide clinical practice (Culliford, 2002).

Given that religious coping (Huguelet, Mohr, Borras, Gillieron \& Brandt, 2006), degree of religiousness (Corrigan et al., 2003) and attendance at religious services (MurraySwank et al., 2007) appear to be particularly prevalent for those with psychosis, research into the unique role of religion in recovery is timely. This study aimed to explore the mechanisms through which religion may influence the recovery of individuals with experience of psychosis.

\section{Method}

\section{Participants}

Participants were recruited from Early Intervention Services, Community Mental Health Teams and voluntary services across the North-West of England. People were invited to participate if they were aged between 16 and 65, had experienced psychosis and considered themselves to be religious. Those unable to; give informed consent, communicate in English, or who were not under mental health services were excluded. There were ten participants, eight male and two female, aged between 25 and 35. Four were Muslim, four Christian and one a Jehovah's Witness. One participant described themselves as religious, but did not identify with a specific denomination.

\section{Design}


This study used an approach informed by social constructivist grounded theory (SCGT; Charmaz, 2006). In contrast to traditional approaches, SCGT denies the concept of an objective reality unmediated by the role of the researcher in constructing an account (Mills, Bonner \& Francis, 2006).

Following ethical approval, an interview schedule was designed in consultation with a service-user. The schedule was flexible, allowing participants to speak freely about their experiences whilst offering direction. It contained questions such as: what role has religion played in your recovery; how has your religion helped your recovery; how has your religion made recovery more difficult; and how have services been able to meet your religious needs. Following initial interviews and early stages of analysis, the schedule was revised with the aim of moving towards theoretical sufficiency.

\section{Analysis}

The principle researcher (SH) listened to recordings and transcribed interviews verbatim, generating familiarity with the data. Transcripts were first analysed by line-by-line opencoding using participants' own terms as codes where possible. Next, the most frequent or significant codes were synthesised to explain larger segments of the data and organise data into categories. Relationships between categories were developed through theoretical coding in order to conceptualise how codes may relate to each other (Charmaz, 2006). Memos were recorded in a research journal consisting of tentative ideas and areas for further exploration, moving towards more analytical concepts in later analysis (Tweed \& Charmaz, 2012). The analysis was reviewed and discussed within the research team.

\section{Researcher Context}


The principle researcher $(\mathrm{SH})$ had experience of investigating recovery in psychosis, which inevitably shaped her views. However, participants were asked to provide their own definitions of "recovery" and "psychosis" at the outset to move towards a shared language.

SH held no particular religious belief which may be associated with a lack of religious knowledge and limit the capacity to fully identify salient information. Participants were asked to clarify unfamiliar terms and given their interview transcripts to check for accuracy. It was acknowledged that SH's position, as a white British female and a mental health professional, might influence participants' disclosures. SH remained mindful of this dynamic to allow greater sensitivity in interviewing and increase attention to inconsistencies.

\section{Findings}

Analysis produced a constellation of processes through which religion appeared to play a role in recovery. Consistent with previous research (Pitt, Kilbride, Nothard, Welford \& Morrison, 2007), recovery held different meanings for different people, such as an ongoing process of learning to live with difficulties, a cure or a change in how society functions.

\section{Use of scriptures and rituals}

The use of religious scriptures and rituals was considered crucial to religion's role in recovery because "the sooner I pray the sooner I get better" (Saeed). The most important influence of religion in recovery was described as "praying them lines what the Imam told me to do, going to the mosque on Fridays" (Tariq).

\section{A genuine connection with God}

Despite their importance; reading scripture and performing rituals were not sufficient without a sense of a genuine connection to God: 
I used to pray for the love of God and I didn't pray because someone forced me to do it, I actually loved God that much, I loved the prophet more than myself...you have to do it from the heart...the person who made you on this planet has not made you and left you like this. He still cares for you...I think faith plays a massive part in recovery. (Saeed)

A reciprocal relationship with a higher power was considered to be a central factor in religion's role in recovery and influenced other categories within present findings.

\section{The struggle to maintain rituals}

Several participants mentioned the consequences of feeling unable to conduct religious rituals because "sometimes I lose my focus...I become quite lazy in sort of worshipping and doing my prayers and I can't concentrate" (Jamal). The consequences of this took on a circular process, whereby some described a sense of self-blame and guilt, further exacerbating symptoms. Reduced engagement seemed to lessen a connection with God and motivation for observance. This meant a minimised, or in some cases, detrimental impact of religion upon the recovery process because "it's through not continuing with your prayers and your rituals that stop you from being religious and sometimes when you leave religion you become unwell...YYou've said to God I don't want you anymore” (Saeed).

Some had adapted to restrictions on engagement in rituals, such as listening to the “Quran on a CD” (Tariq) or finding novel ways of engaging with scriptures: "I couldn't read or focus but I could copy the bible and it made me feel better" (Sarah).

\section{Guidelines for living}

Religious belief and scripture offered most participants a set of guidelines which helped them to navigate their difficulties and facilitated recovery: 
A lot of time I'm a bit lost, I don't know what to do, but the bible just guides me... telling you to help people, love people... and I feel like the word of the bible is just guiding me through. (Sarah)

The importance of helping others and performing good deeds was a prominent process which held addictive, uplifting qualities and brought participants closer to God. Some also felt that scriptures encouraged forgiveness:

I tried holding on all this anger and not forgive people and this made my life really miserable and made my illness worse...forgiveness is very important, every time I think about it I say in my prayers, God forgive the person that hurt me and that's made me feel better. (Sarah)

Having a set of guidelines helped some participants moderate their behaviour to bring them closer to God, such as "not using bad language, by not smoking, by having good conduct...by not getting drunk...by not abusing my body" (Andy).

Conversely, others indicated that "having strict guidelines, having strict rules as a kid can make you almost ill" (Saeed). Guidelines heavily imposed by family or religious communities could produce feelings of guilt and adversely influence recovery.

\section{Choice and Control}

The importance of choice and control over religious beliefs and practices was highlighted. Participants described becoming "your own being, you believe in what you wanna be, you take different aspects out of different books" (Ian). Using personally salient parts of scripture and individual belief systems represented a strategy to achieve autonomy from society, religious communities and family. Some appeared to be describing a process of developing their own religious identities whereby "it should be up to that person to have that choice...if 
you have belief in yourself and believe what you believe then it's not put into you...it's not forced" (Alan).

Personal choice was also important in integrating religion into mental health services “on an I want to basis so they don't force it in there" (Mary). Most participants described a lack of available facilities, since “once you're in hospital it's all restricted isn't it...and you can't go to no mosque or no church" (Tariq). However, others felt that religion and mental health should remain separate.

The importance of control was echoed in efforts to take an active role in recovery, rather than relying on God, for example, “God's stopped me from doing yourself in but he's powerless, gotta self-help sort of thing" (James). Others preferred to externalise control by being "in the world where only God can help you" (Adam). However, some held alternating views such as "before you get better you have to put effort to...but sometimes it's not in the human being's hands to get better" (Saeed).

\section{Relating to others}

Participants explained that religion can both enhance and hinder connections with others. Shared beliefs with friends and family was facilitative of recovery because "we can move forward together and like when I'm feeling down or unwell she'll pray for me and stuff and...when she's unwell I'll pray for her" (Ian). Likewise, joint engagement in religious activities such as opening fasts and religious conferences was viewed to be helpful. Belonging to a religious community offered a non-judgmental space to be accepted and socialise: "I feel like they are not prejudice about me having psychosis. They are very kind and helpful to me and when I need a person to talk to they are there for me" (Sarah).

Others highlighted how religious involvement could lead to disconnection through fear of being "persecuted" (Ian): 
I'll pray in my room and some guy walked in...this guys mad, what's he doing, praying to a wall, so, I didn't want to...bring my religion into that place...I'm a British born person, mix with everyone, make friends, nice guy, easy going, I didn't want to bring my religion into that. (Saeed)

Moreover, some recalled receiving judgement from religious communities. Psychosis was considered as "a taboo subject" where "people don't really take it seriously; people think you're weird or you're putting it on" (Jamal). Some developed strategies to avoid disconnection such as managing disclosure of beliefs and hiding rituals. As well as fearing others' perceptions, some perceived themselves, as "over-religious" (Jamal) in the past, to the detriment of family and social relationships:

I was too much into just one way of spirituality and was neglecting everything...I was out of balance before. I was too much on to a spirit, which my heart and soul are still there but I have to play a part with my family. (Adam)

\section{Enhancing Psychological Well-Being}

\section{Self-esteem and self-belief}

Participants discussed religion's ability to form "a healthy view of myself" (Andy) and to learn "what's happening isn't your fault and it is going to get better" (Mary). One mechanism through which this occurred was in the reduction of shame associated with difficult experiences:

You just can’t forgive yourself, you just have so much guilt and this pain of things...I feel so dirty but religion just makes me feel better...now I'm more in the recovering stage. I can talk about these things without being ashamed. (Sarah)

Religion also allowed participants to feel "special" (Tariq), fostered creativity, and encouraged to "achieve your best" (Saeed). 


\section{Hope and purpose}

Participants considered hope and purpose to be crucial to recovery with religion contributing to their development. This occurred through processes such as providing hope for the future, a better world and the afterlife through religious teachings and a relationship with God:

I've spoken to God and spoken to Jesus about things it's like it's ok...it is going to get better, it's not going to be like this forever which makes you feel

reassured...something a lot better is going to happen at the end which is gonna be a lot better than what you're going through. (Mary)

Some expressed the belief that events promised within scripture would lead to a better society in the future because "when you're a believer, you know good days are going to happen...and this is what we're battling for". (Adam)

\section{Emotional well-being}

Religion was said to influence emotional well-being by providing a soothing effect, bringing "peace of mind" (Jamal) and enhancing the ability to manage strong emotions by "stepping back from a situation" (Andy). Participants described feeling "uplifted” (Jamal) by religious services and experienced increased positivity and productivity. For some, religion had a cleansing effect by allowing them to feel forgiven by God and alleviate feelings of guilt through processes such as confession, repentance and rituals.

Finally, under this theme, some said that religion kept them safe from self-harm and suicide. This occurred through scriptures framing suicide as an "evil sin" (Saeed), being protected by relatives in heaven and directly through God's intervention:

My last overdose landed me in hospital so the amount that I'd taken, it probably could have killed me but it didn't, so he obviously wants me here for a reason else he would have killed me, let me go. (Mary) 
On the other hand, it was suggested that "when you're having a really rough time...you know that heaven is all gonna stop which can then lead onto trying to kill yourself" (Mary).

\section{Making sense of experiences}

During the onset of psychosis, participants described feeling "really scared" (James) and questioned the origin of their experiences through considering multiple explanations. Various appraisals were presented between and within interviews, such as; illness, a punishment or test, the result of stress and trauma, drug use, invasion by the devil and a jinx. Drawing upon family, medical professionals, scripture and religious leaders; participants weighed up the different explanations.

Problematically, the separation between mental health services and religious organisations meant that participants often received conflicting views, making it difficult to arrive at an explanatory framework:

The most conflicting message I had was the diagnosis of the psychosis like people saying that it's ok God's got it in hand, everything's gonna be fine, and then they're saying no you're psychotic you need medication, other people saying no you don't need medication, yes you do, no you don't...will somebody please just tell me what is going on. (Mary)

Nevertheless, participants had developed strategies to consider the evidence for appraisals. Some turned to scripture for religious explanations. Others relied on medical professionals to confirm an illness explanation since "the whole diagnosis of the psychosis and that made me realise that...all my symptoms linked up, linked to the psychosis and not to what I thought it was, which was the devil oppressing me" (Mary). Additionally, "common sense" (Ian) and "weigh(ing) up your pros and cons" (Mary) were used to make sense of different explanations. 
The development of an explanatory framework was considered key since "when you don't know, it's harder to deal with. When you do know, it's a lot easier to deal with" (Mary). In the absence of a structure for understanding experiences or in feeling torn between explanations, recovery was delayed:

Alcohol and drugs and things have got a lot to do with it...I've thought I was in the SAS...I thought it was people trying to make it easier to kill me, I've thought everything...Maybe I'm still clinging onto that it's somebody there and maybe that's why I can't recover. (James)

The final finding relates to the shifting nature of understandings. For some, religion had allowed them to re-appraise their experiences, for example, in reframing what had previously been considered a "jinx" to a "gift" (Alan). Conversely, some benefitted from developing a medically-based explanation:

You don't know what else it could be it's quite easy to think well blame it on the religion. It's quite easy to say it's all God's fault...but then you realise that it's not, it's something else, then you...look back and reassess what happened and you can try and make the links between what happened and the diagnosis that you've got...it makes it a lot easier to deal with. (Mary)

\section{Discussion}

Recovery is best conceptualised as a personal journey with individual meaning. Consistent with previous research, present findings showed that religion can play a role in developing dimensions beneficial to recovery. However, it can also foster self-blame, guilt and alienation. These findings explore the processes and mechanisms through which religion may influence recovery. 
The capacity for religion to both enhance and hinder social connection has been documented (Fallot, 2001) and is evidenced here. Our findings suggest that participants negotiate this conflict and direct the way they are perceived by using strategies to reduce negative evaluation such as; discretionary disclosure of religious beliefs, experiences of psychosis and displays of religiousness.

A central finding here was in the essential role of a genuine, reciprocal connection with a deity and this was felt to influence other categories. Losing opportunity for religious observance through hospitalisation or fear of social disapproval curtailed a sense or connection, meaning rituals lose meaning and recovery is limited by generating feelings of guilt and loss. Similarly, an externally imposed sense of religious commitment was considered less beneficial in recovery due to a lack of intrinsically meaningful connection with God.

Religious practice may also contribute to recovery through other mechanisms identified as beneficial in psychological well-being. For example, there is evidence from the mindfulness literature that being present in the moment can positively impact upon mental health; this being a potential feature of religious practice. Additionally, maintaining meaningful activity in the face of psychological adversity can support coping.

The way psychosis is appraised can affect its impact and religious appraisals can be positive or negative (Phillips \& Stein, 2007). Individuals assimilate a range of information sources into a personally meaningful and acceptable understanding of experiences. This contributes to recovery, whilst struggling to develop an explanatory framework appears to hold back recovery. The important point here is that one's understanding of experiences is personally acceptable, rather than necessarily culturally acceptable.

\section{Clinical Implications}


To support recovery, it is essential that mental health services consider the religious needs of service-users. Asking about religion at assessment is emphasised in best-practice policy (National Institute of Mental Health in England, 2003) but clinicians generally neglect this or wait until it is raised by the service-user (Crossley \& Salter, 2005). Service-users may be initially reluctant to discuss such issues however religion could be explored during continued assessment alongside a developing therapeutic relationship (Coyle \& Lochner, 2011).

A core contribution of religion to recovery lies in the use of scripture and rituals in supporting service-users to maintain a relationship with the deity. Potential for recovery is adversely affected where there is a lack of opportunity for religious expression or fear of social censure. Participants highlighted the lack of facilities within services to meet religious needs, particularly for inpatients. We recommend that services should facilitate opportunities and provide the necessary means to foster a relationship with God by offering opportunity for religious observance. This could include technological methods within restrictive environments such as the use of Compact Discs and podcasts. Additionally, where appropriate, hospital chaplains should be involved in service-users' care (Dein, 2004) as religious representatives might have a role to play for individuals struggling to maintain connections with God.

Support with spiritual wellbeing should continue following discharge and be available within community services. Recovery appears enhanced when an individually meaningful understanding of experiences is developed. Conflicting advice from mental health services and religious organisations can potentially hinder recovery. Mental health and religious organisations working together would allow the opportunity for shared perspectives and hopefully promote recovery.

Religion plays complex and dynamic functions in recovery. Beliefs and practices may be beneficial to some and problematic to others. Some aspects may be both helpful and 
harmful within an individuals' recovery. Information from assessment should inform psychological formulations, which incorporate how religion is used as a positive resource as well as problems resulting from religion and strategies used to manage this. This offers opportunities to explore how service-users make sense of their experiences and any conflict within this process.

Therapeutic intervention should include religious issues for those to whom it is pertinent. This could be achieved through denomination-specific adaptations to existing approaches (e.g. Hamdan, 2008; Hawkins, Tan \& Turk, 1999) or through making space for the discussion of religious issues. Group programmes have been developed (e.g. Kehoe, 1998; Revheim \& Greenberg, 2007) and offer a therapeutic space to explore feelings and concerns pertaining to religion. Key therapeutic elements of these lie in the provision of opportunities to discuss issues otherwise neglected in mental health services (Fallot, 2001) and could enhance self-esteem by offering a space to discuss positive and challenging religious experiences (Lukoff, 2012).

\section{Limitations and Future Research}

It is acknowledged that there are limitations with the current study. Firstly, participants may have held expectations about the religious beliefs of the researcher. Several described pathologising experiences in mental health services, which could have resulted in censorship of beliefs.

The sample size was small and represented only a narrow range of denominations. It was also limited in terms of age range and gender balance. Only participants involved with mental health services participated. Those living independently of services and potentially further along their recovery journey and those not seeking help from services were excluded and may hold differing views to the participants in this study. It could be argued that the 
small sample was insufficient to achieve theoretical saturation. However, it is acknowledged that we used a grounded theory informed approach and it is hoped that adapting interview questions in light of developing categories provided elaboration of categories, illuminated negative cases and helped us move towards theoretical sufficiency (Dey, 1999).

Despite this, the study offers some novel insights into the role of religion in recovery from psychosis. Given the lack of research in this area future studies might adopt a larger and more diverse sample to build upon our findings and explore the experiences of those not represented here.

\section{References}

Brewerton, T.D. (1994). Hyperreligosity in psychotic disorders. Journal of Nervous and Mental Disease, 182, 302-304. doi: 10.1097/00005053-199405000-00009

Charmaz, K. (2006). Constructing Grounded Theory: A Practical Guide Through Qualitative Analysis. London: SAGE Publications Ltd.

Cornah, D. (2006). The Impact of Spirituality on Mental Health: A Review of the Literature. London: Mental Health Foundation.

Corrigan, P., McCorkle, B., Schell, B. \& Kidder, K. (2003). Religion and spirituality in the lives of people with serious mental illness. Journal of Community Mental Health, 39 (6), 487-499. doi: 10.1023/B:COMH.0000003010.44413.37

Coyle, A. \& Lochner, J. (2011). Religion, spirituality and therapeutic practice. The Psychologist, 24 (4), 264-266. http://www.thepsychologist.org.uk

Crossley, J.P. \& Salter, D.P. (2005). A question of finding harmony: A grounded theory study of clinical psychologists' experience of addressing spiritual beliefs in therapy. Psychology and Psychotherapy: Theory Research and Practice, 78, 295-313. doi: $10.1348 / 147608305 \times 26783$ 
Culliford, L. (2002). Spiritual care and psychiatric treatment: an introduction. Advances in Psychiatric Treatment, 8, 249-258. doi: 10.1192/apt.8.4.249

Dein, S. (2004). Working with patients with religious beliefs. Advances in Psychiatric Treatment, 10, 287-294. doi: 10.1192/apt.10.4.287

Fallot, R.D. (2001). Spirituality and religion in psychiatric rehabilitation and recovery from mental illness. International Review of Psychiatry, 13, 110-116. doi: 10.1090 .09540260120037344

Fallot, R.D. (2007). Spirituality and religion in recovery: some current issues. Psychiatric Rehabilitation Journal, 30 (4), 261-270. doi: 10.2975/30.4.2007.261.270

Hamdan, A. (2008). Cognitive restructuring: an Islamic perspective. Journal of Muslim Mental Health, 3, 99-116. doi: 10.1080/15564900802035268

Hawkins, R. S., Tan, S.-Y., \& Turk, A. A. (1999). Secular versus Christian inpatient cognitive-behavioral therapy programs: Impact on depression and spiritual wellbeing. Journal of Psychology and Theology, 27, 309-331. http://journals.biola.edu

Huguelet, P., Mohr, S., Borras, L., Gillieron, C. \& Brandt, P. (2006). Spirituality and religious practices among outpatients with schizophrenia and their clinicians. Psychiatric Services, 57 (3), 366-372. doi: 10.1176/appi.ps.57.3.366

Huguelet, P. \& Koenig, H.G. (2009). Religion and Spirituality in Psychiatry. New York: Cambridge University Press.

Kehoe, N.C. (1998). Religious-issues group therapy. In Fallot, R.D. (Ed.) Spirituality and religion in recovery. San Francisco, CA: Jossey-Bass Publishers

Longo, D.A., \& Peterson, S.M. (2002). The role of spirituality in psychosocial rehabilitation. Psychiatric Rehabilitation Journal, 25 (4), 335-340. doi: 10.1037/h0095004 
Lukoff, D., Lu, F., \& Turner, R. (1992). Toward a more culturally sensitive DSM-IV: Psychoreligious and Psychospiritual Problems. Journal of Nervous and Mental Disease, 180(11), 673-682. Doi: 10.1097/00005053-199211000-00001

Lukoff, D. (2012). Spirituality and Psychosis. In Geekie, J., Randal, P., Lampshire, D. \& Read, J. (Eds.) Experiencing Psychosis: Personal and Professional Perspectives. (pp.66-77). East Sussex: Routledge.

Menezes, A. \& Moreira-Almedia, A. (2010). Religion, spirituality and psychosis. Current Psychiatry Reports, 12, 174-179. doi: 10.1007/s11920=010-0117-7

Mills, J., Bonner, A. \& Francis, K. (2006b). Adapting a constructivist approach to grounded theory: Implications for research design. International Journal of Nursing Practice, 12, 8-13. doi: 10.1111/j.1440-172X.2006.00543.x

Murray-Swank., A., Goldberg, R., Dickerson, R., Medoff. D., Wohlheiter, K., Dixon, L. (2007). Correlates of religious service attendance and contact with religious leaders among persons with co-occurring serious mental illness and type 2 diabetes. The Journal of Nervous and Mental Disease, 195 (5), 382-388. doi:

10.1097/01.nmd.0000253801.18367.a5

National Institute for Mental Health in England (2003). Inspiring Hope: Recognising the Importance of Spirituality in a Whole Person Approach to Mental Health. Leeds: Author.

Pargament, K.I., Kennell, J., Hathaway, W., Grevengoed, N., Newman, J. \& Jones, W. (1988). Religion and the problem-solving process: Three styles of religious coping. Journal for the Scientific Study of Religion, 27 (1), 90-104. doi: 10.2307/1387404 
Phillips, R.E. \& Stein, C.H. (2007). God's will, God's punishment or God's limitations? Religious coping strategies reported by young adults living with serious mental illness. Journal of Clinical Psychology, 63 (6), 529-540. doi: 10.1002/jclp.20364

Phillips, R.E., Lukoff, D. \& Stone, M.K. (2009). Integrating the spirit within psychosis: alternative conceptualizations of psychotic disorders. The Journal of Transpersonal Psychology, 41 (1), 61-80. http://www.atpweb.org/journal

Pieper, J. Z. T. (2004). Religious coping in highly religious psychiatric inpatients. Mental Health, Religion, and Culture, 7 (4), 349-363. doi: $10.1080 / 13674670410001719805$

Pitt, L., Kilbride, M., Nothard, S., Welford, M., \& Morrison, A.P. (2007) Researching recovery from psychosis: A user-led project. Psychiatric Bulletin, 31, 55-60. doi: 10.1192/pb.bp. 105.008532

Revheim, N. \& Greenberg, W.M. (2007). Spirituality matters: creating a time and place for hope. Psychiatric Rehabilitation Journal, 30, 307-310. doi:

10.2975/30.4.2007.307.310

Sullivan, W.P. (1998) Recoiling, regrouping and recovering: First person accounts of the role of spirituality in the course of serious mental illness. In Fallot, R.D (Ed.) Spirituality and Religion in the Recovery from Mental Illness. (pp. 25-33). San Francisco: JosseyBass publishers.

Tepper, L., Rogers, S. A., Coleman, E. M., \& Malony, H. N. (2001). The prevalence of religious coping among persons with persistent mental illness. Psychiatric Services, 52(5), 660-665. doi: 10.1176/appi.ps.52.5.660

Tweed, A. \& Charmaz, K. (2012). Grounded theory methods for mental health practitioners. In Harper, D. \& Thompson, A.R. (Eds.) Qualitative Research Methods in Mental 
Health and Psychotherapy: A Guide for Students and Practitioners. (pp.131-147).

West Sussex: John Wiley \& Sons Ltd.

Yangarber-Hicks, N. (2004). Religious coping styles and recovery from serious mental

illness. Journal of Psychology and Theology, 32 (4), 305-317. http://journals.biola.edu 